The International Journal of Multimedia \& Its Applications (IJMA) Vol.3, No.1, February 2011

\title{
SELECTION SORTING ALgORITHM VISUALIZATION USING FLASH
}

\author{
Hadi Sutopo \\ Department of Informatics, Universitas Persada Indonesia YAI, Jakarta, Indonesia \\ hadietopazart.info
}

\begin{abstract}
This paper is intended to develop an algorithm visualization, particularly selection sorting for an Algorithm and Programming course. Algorithm visualization technology graphically illustrates how algorithms work. This visualization can be used to explain how all data move to the proper position in order to be sorted in a display computer for education. This research consists of 6 steps which are concept, design, obtaining content material, assembly, testing, and distribution. During the testing step, the application is run and checked to confirm that it performs exactly what the author has intended and the students can learn selection sorting algorithm by studying the visualization. Subjects of the research were students at Department of Informatics Universitas Persada Indonesia YAI for implementation of the learning. The data were analysed using the analytic descriptive method and interpreted in a narrative way based on the research findings. The algorithm visualization indicates that students increase their motivation and ability to program variety of sorting in programming language they learn.
\end{abstract}

\section{KEYWORDS}

Multimedia, Algorithm, Sorting, Flash movie, ActionScript

\section{INTRODUCTION}

Learning is a necessity in life, since his birth till the ends. As a human, we learn to be able to achieve our independence and to adapt to various environmental changes [1]. Nowadays, due to globalization and proliferation of technology, computer education in Indonesia becomes great demand for students. One of the favourite subjects in computer education is Algorithm and Programming, which is now held in many courses as main subject. The subject is studied by first grade students, because it as the basic knowledge to be implemented in computer programming. Students have to understand algorithm clearly if they want to be a good programmer.

Sorting is a common algorithm studied in information technology, computer science, and engineering. In computer science particularly algorithm, selection sorting algorithm is an algorithm for sorting a series of data. This concept is difficult to be understood for students who study computer science, especially creating coding in programming language.

Therefore one of the solutions is to provide the students algorithm visualization. Many of the phenomena treated in engineering are dynamic and/or three dimensional; often these phenomena are very difficult to be represented in the conventional print media, however it is anticipated that visualization has the capacity to do a much better job. Visualization is gaining its popularity to implement in education institutions either in distance learning or in blended learning. The development of algorithm visualization should be able to observe the condition of student concerned, due to the changes in paradigm of learning which is from teacher-centred learning to student-centred learning [2]. 
Algorithm visualization uses computer graphics or multimedia to show the actions of an algorithm step by step. In this research, the algorithm visualization is used to help students understand the concept of selection sort algorithm and creating coding to visualize it.

Our goal is to develop algorithm visualization of Selection Sorting Algorithm. The visualization show how all data move to the proper position in order to be sorted. It can be easily understood by students how a the algorithm should be implemented in coding.

\section{SORTING}

In computer science and mathematics, a sorting algorithm is an algorithm that puts elements of a list in a certain order [3]. The most-used orders are numerical order and lexicographical order. Efficient sorting is important for optimizing the use of other algorithms (such as search and merge algorithms) that require sorted lists to work correctly; it is also often useful for canonicalizing data and for producing human-readable output. More formally, the output must satisfy two conditions: (1) The output is in non decreasing order (each element is no smaller than the previous element according to the desired total order); and (2) The output is a permutation, or reordering, of the input.

Since the early of computing, the sorting problem has attracted a great deal of research, perhaps due to the complexity of solving it efficiently despite its simple, familiar statement. Sorting algorithms are prevalent in introductory computer science classes, where the abundance of algorithms for the problem provides a gentle introduction to a variety of core algorithm concepts, such as big $\mathrm{O}$ notation, divide and conquer algorithms, data structures, randomized algorithms, and case analysis.

\subsection{Selection Sort}

A selection sort is one in which successive elements are selected from the file and placed in their proper position [4]. The following program is an example of a straight selection sort. The largest number is first placed in the nth position, the next largest is placed in position $n-1$, and so on. Below is the procedure of selection sorting.

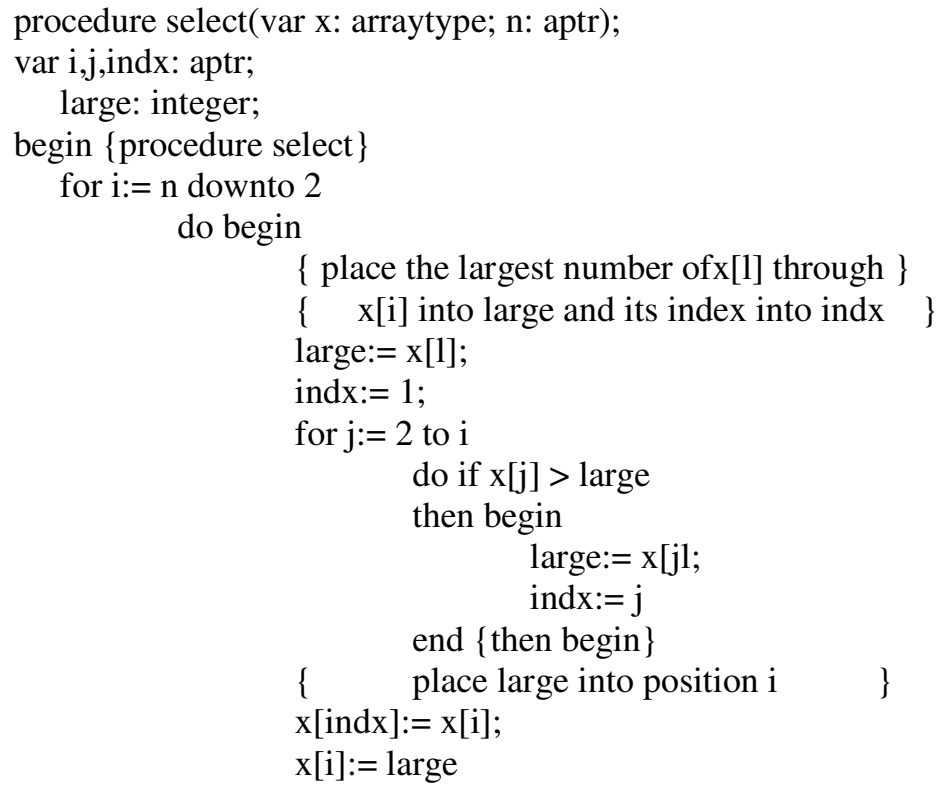


end; $\{$ procedure select $\}$

\subsection{Related Works}

Selection sort algorithm [3] arranges array elements in order by first finding the minimum value in the array. Depending on how the array is being arranged, then swapping it with the array element that is in its correct position. The process is repeated with the second smallest value until the array is sorted. The process creates two distinctive halves within the array, the one are array elements that have been sorted and the other are array elements that have not been sorted. Below is an example of sorting processing.

There are numbers that are going to be sorted:

$32,4,1,12,19$

The first process is comparing 32 to every number in the range, and swap it for the lowest one. In this, the first loop is swapping 32 with 1 , which is currently the lowest number in the range. The numbers are now look like this:

$1,4,32,12,19$

The second process is continued by checking 4, the second element, with the rest of the elements. There is, however, no value after 4 that is lower than it, so it will have to stay at the location. The range still looks like this:

\section{$1,4,32,12,19$}

The third process is checking the third element in the range, 32. It turns out that 12 is the lowest value within the range of numbers left, so the process swaps 32 and 12 . The numbers will now look like this:

$1,4,12,32,19$

The next process is the fourth checking, and as 19 is the lowest number, and is lower than 32, so the numbers are swapped to each other and it is the end of the sorting. The sorted numbers are now look like this:

$1,4,12,19,32$

\section{ViSUALIZATION}

Visualization is presenting data or information that used in science, engineering, medical, business, and others. Numerical simulations often produce data files that is contains data values. The data are converted to a visual form that is helpful for the user in analysing his/her problem. Visualization for science, engineering, and medical presents graphical form information presentation. And the term business visualization is used in connection with data sets related to business, management, social, industry, and other non scientific areas [5].

\section{Multimedia}

Multimedia is a combination of text, images, sound, animation, and video delivered via computer or electronic and digital equipment [6]. Using together multimedia elements such as images and animation that are equipped with sound, video clips, and text, will be able give clear 
meaning to those who need it. Vaughan stated that multimedia can bring radical changes in the learning process, from passive student learning to active student learning.

The word multimedia is a combination derived from multiple and media [7]. We define digital multimedia as any combination of text, graphic (still and animated), sound, and motion video delivered to the user by a computer. The computer is an intrinsic part of multimedia. All these elements - text, graphics, sound, and video - are either computer-generated or transmitted through a computer. Multimedia systems are used in education, presentations, information kiosks, and gaming industry. The power of computer allows users to interact with the programs. Since interactivity is such a powerful concept, many experts in the field of multimedia consider interactivity as an integral part of multimedia.

In a multimedia system, if the user has the ability to control the delivered elements and timing, the system is called an interactive system [8]. There are different devices to provide end-user interactivity. Almost all tools today support the use of keyboard and mouse, button, and even touch screen. Buttons are on-screen objects that will produce some response when the end user clicks the mouse or touches them. The pushbutton control in Windows dialogue boxes is an example of a button. Authoring of buttons involves defining the button appearance on screen, the location, and the action when clicked. Assembly tools that support buttons will provide features to do all three things.

\section{RESEARCH DESIGN}

This section presents the method of developing selection sorting algorithm visualization that is used in this research. This research uses Multimedia Development Life Cycle (MDLC) [9]. Authoring is somewhat like making a feature film, a movie, and there are many steps to the process. Multimedia Development Life Cycle, a typical multimedia systems development, may involve the following six major steps presented in Figure 1, as follows:

1. Concept. The objective for the project is defined, and the type of the application is specified. In the film production, this is the stage at which the producer decides the kind of application to take and the subject to be.

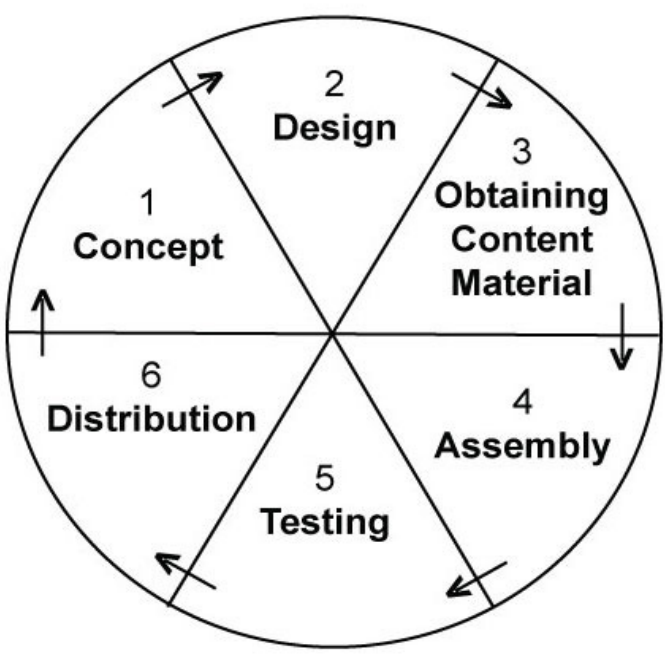

Figure 1. Multimedia development life cycle 
2. Design. This is the process of deciding in detail what will be in the project and how it will be presented. This stage includes script writing, storyboarding, making navigation structure and some design steps.

3. Obtaining content material. During this stage all the data, audio, video and images for the project are collected in appropriate digital formats. In the course material, this would be the production stage, where all the scenes for the multimedia application are set up.

4. Assembly. In this step, the overall of the project is built, the visualization of selection sorting algorithm is assembled, and any interactive features are built. The tool for this stage of authoring is Adobe Flash.

5. Testing. During testing, the application is run and checked to confirm that it performs exactly what the author has intended. We have performed our experiment in two phases, preliminary testing and main field testing. At the first phase, the system is evaluated by peers and experts. The subjects research for implementation of the revised model in the main field testing are informatics students.

6. Distribution. In this step, the application is reproduced and delivered to students for their use. The distribution can be form application files that can be run on a mobile device.

The object of the research will be the development of multimedia application particularly selection sorting visualization. The research location will be conducted at Department of Informatics Universitas Persada Indonesia YAI, Jakarta. Respondents consist of students who are studying Algorithm and Programming course. This research is conducted six steps, but it is done until fifth step. The last step Distribution, dissemination at all universities in Indonesia, is not done this time, because the objective of the application is supporting learning process for students at Univarsitas Persada Indonesia YAI.

\section{DISCUSSION}

The multimedia application is developed to visualize the selection sorting algorithm. Developing the multimedia application involves some steps as follows:

\subsection{Concept}

To illustrate how to develop a multimedia application that contains visualization of selection sorting algorithm in Adobe Flash, the first step is to define the learning objectives [13]. The research objective is to encourage students develop sorting application in a particular programming language. The visualization has to support learning Algorithm and Programming course.

\subsection{Design}

The second step is developing a navigation structure and storyboard of the selection sorting algorithm visualization. First, it establishes lateral thought processes, helping to break down the navigation structures that are usually embedded in traditional approaches to course delivery. Second, it can result in an overview based on quite abstract design, which in turn generates fresh implementation. Third, it provides a storyboard for identifying relationships between the components. Navigation structure [10] is essential to design an interactive multimedia application as shown in Figure 2. 


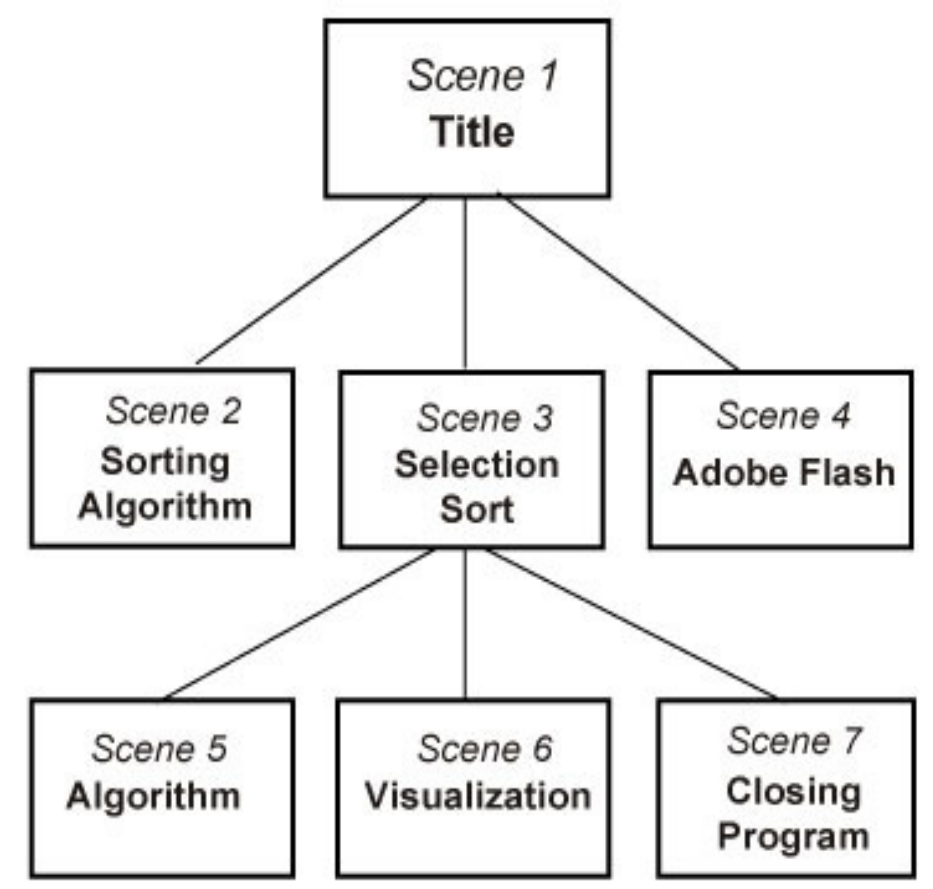

Figure 2. Navigation structure

\subsection{Obtaining Content Material}

The third step is obtaining content material. During this stage all the data, audio, video and images for the project are collected in appropriate digital formats. They can be collected from inside documentation and outside resources.

\subsection{Assembly}

The fourth step is authoring and ActionScript programming. ActionScript [11]. is the programming language that enables us to use Adobe Flash Professional CS4 to create highly interactive, multimedia-based Web sites, product demo, teaching materials, and more. The published application can be run on any computer that is provided with Flash Player. ActionScript is a language that bridges the gap between what we understand and what Flash understands. Like all languages, ActionScript contains many different elements, such as words, punctuation, and structure - all of which we must employ properly to get our Flash project to conduct the way we want it to [12].

To develop Scene 6 in Flash, take the following steps:

1. Create a new Flash Document.

2. Use Text Tool to make five input text fields, and named their variables "in1", "in2", "in3", "in4", and "in5". Convert them into Graphic symbol named "data1" ... "data5".

3. Drag all the graphics symbol from the Library into the stage. Create circles for the background of all instances. 
The International Journal of Multimedia \& Its Applications (IJMA) Vol.3, No.1, February 2011

4. Create Dynamic Text with the variables name "Out" to present the information of the sorting process.

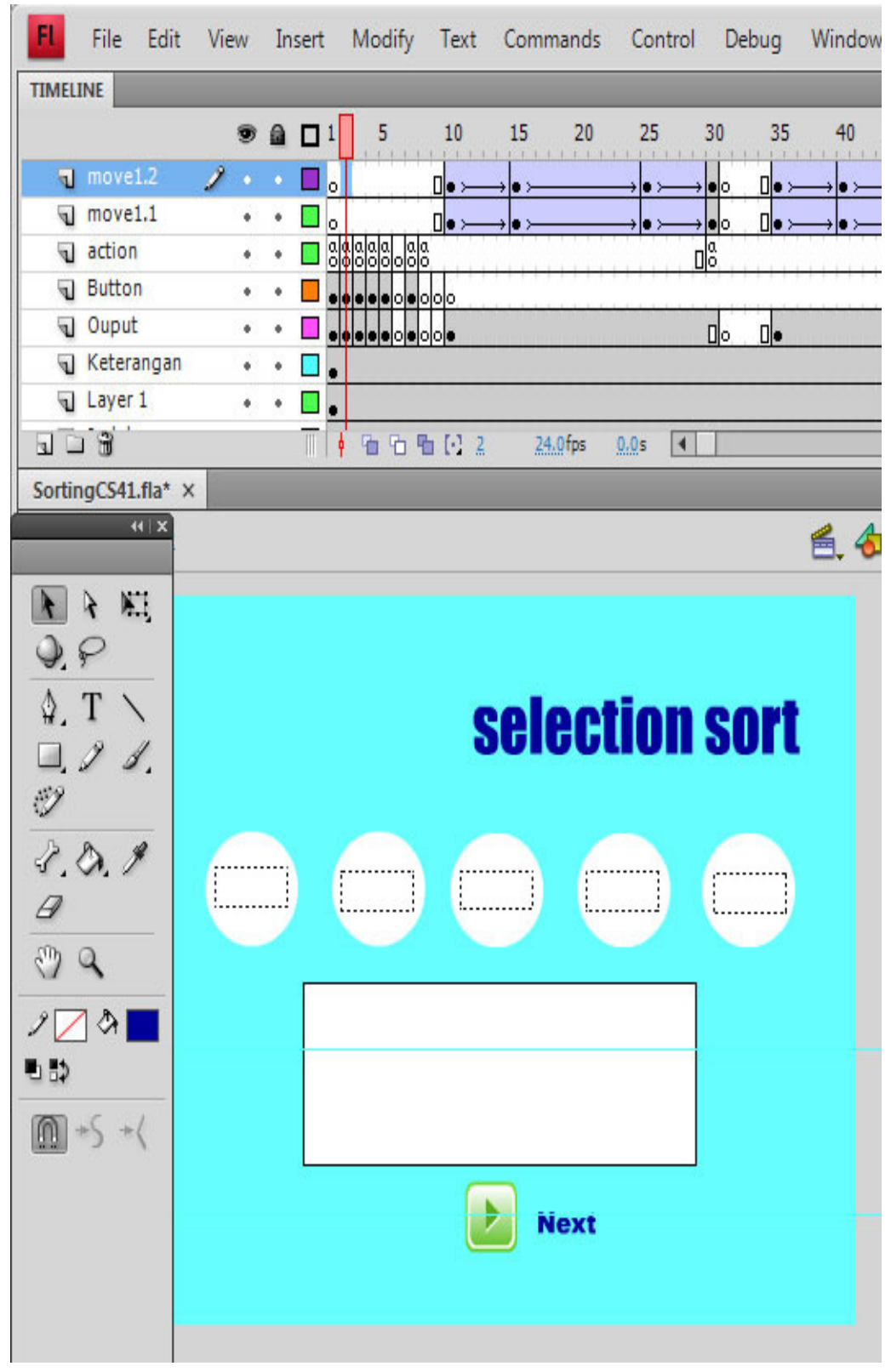

Figure 3. Stage design in Flash document 
5. There are five elements of array, Let us begin with $\mathrm{i}=0$, create new layer to place buttons. At frame 1, create button Next as can be seen in Figure 3, with script as follow:

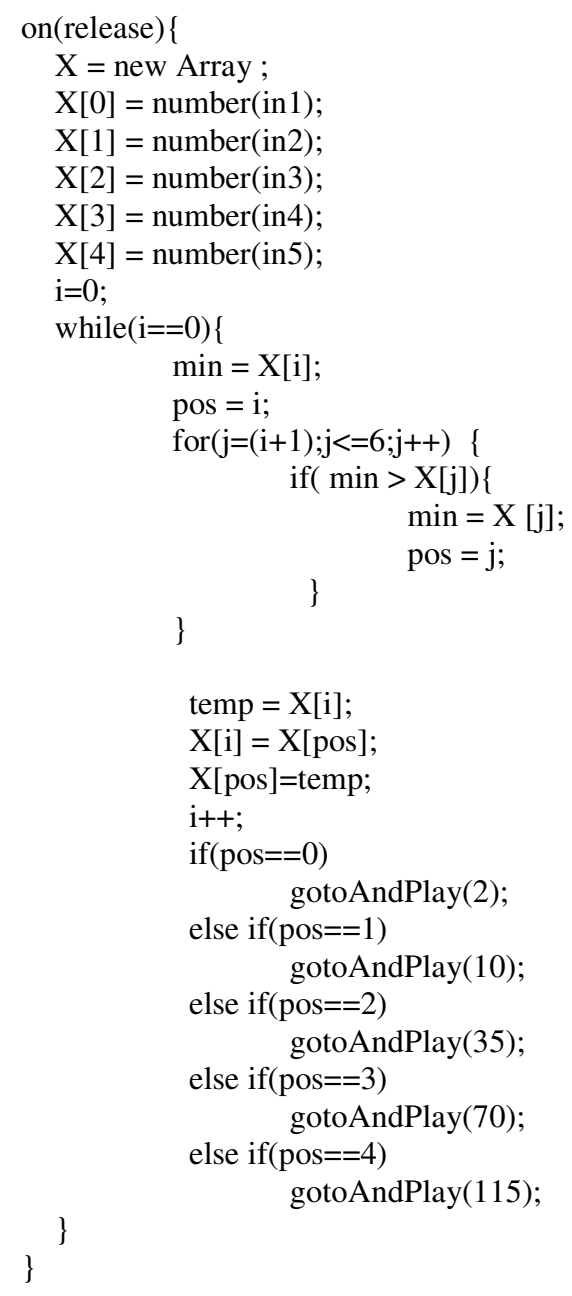

The script generates to create an array that five input data to be it's element [13]. The first element is supposed as the minimum of all the array elements. If the the value of the second element is less then the value of the first element, the two position of elements are changed to each other. Then the display moves to frame 10. The same solution is done for the other element if it's value is less then the value of the first element. Figure 3 shows the stage with button Next.

6. Create new layer named "Action" to place the script showing the display of the data in the field text Output, as follows:

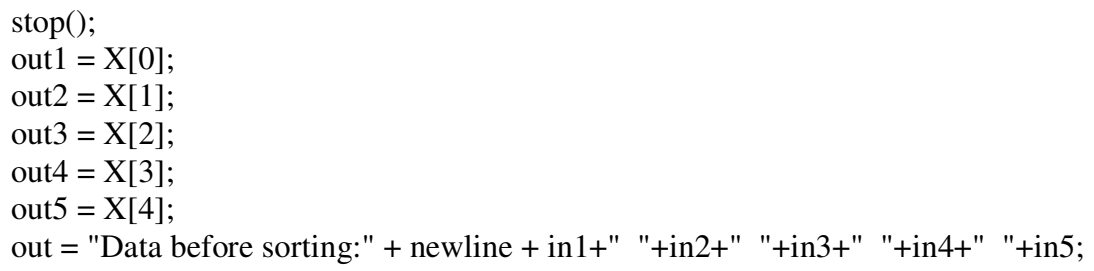




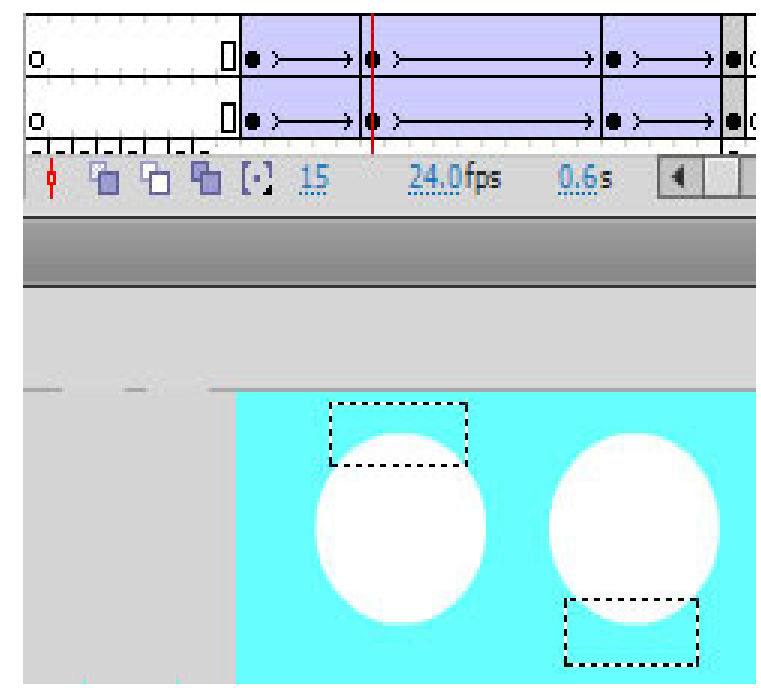

Figure 4. Tweening animation that changes the location of two elements of array

7. Create new layer and make a motion tweening animation to present the movement of the first element and second element of array changes., as can be seen in Figure 4. Similarity, create motion tweening animations to present the changes between the first and the other elements.

8. Create new layer and make a motion tweening animation to present the movement of the second element and the other elements. Similarity create some animations present the changes between the second and the other array elements, the third and the other array elements, and the fourth and the fifth array elements

9. Repeat the activities number 5 to 8 for $\mathrm{i}=1$ until $\mathrm{i}=4$

\subsection{Testing}

The fifth step is Testing, the application is run and checked to confirm that it performs exactly what the objectives are performed. In the application, this is similar to screening, where the application or parts of it are viewed and approved by the lecturer or his or her assistance. The next Flash movie demonstrates how selection sorting is visualized. Flash takes the input data, performs calculation, and then returns the calculated results back to output text field. Figure 5 presents a Flash movie with input text fields and animation of changes data position during the sorting process. 

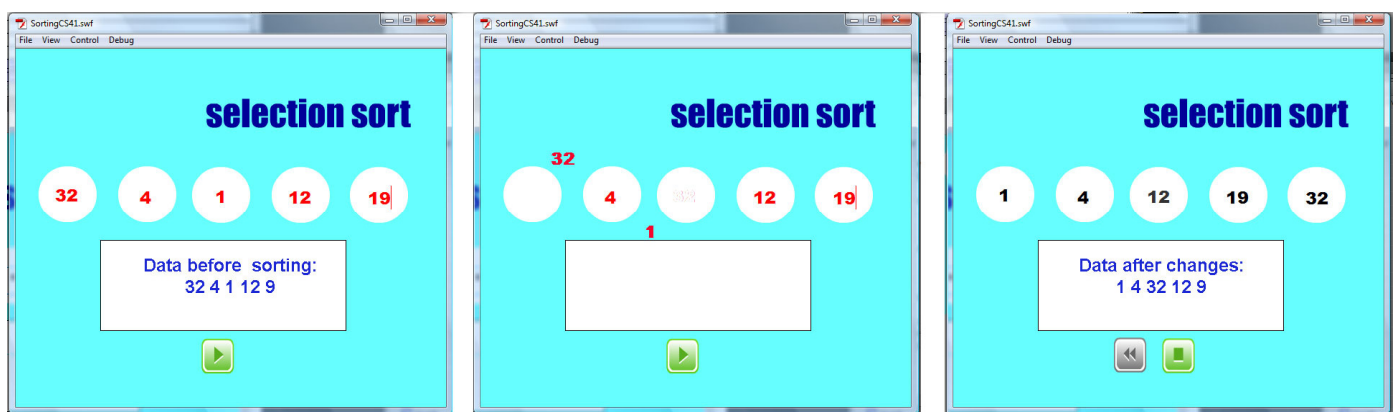

Figure 5. Flash movie presents the animation of the first and second changes process

The experiment of the research is performed in two phases, preliminary testing and main field testing. At the first phase, the system is evaluated by peers and experts. They argued that the algorithm visualization can be used by lecturer to explain selection sorting concept in class. They wanted the selection method will be completed with bubble sort, insertion sort, and the other method.

The second phase is evaluating by students at the Department of Informatics Universitas Persada Indonesia YAI for implementation of the learning. The data were analysed using the analytic descriptive method and interpreted in a narrative way based on the research findings. The visualization and the interactivity have been well tested by the students. The first testing is sorting with integer data, they are sorted properly as can be seen in Figure 6. The second testing is sorting with two integer data that have the same value, and selection sort presents elements with the same value are in the sequential place, as can be seen in Figure 7. The third testing is sorting with integer and real data type, they are sorted properly, as can be seen in Figure 8.
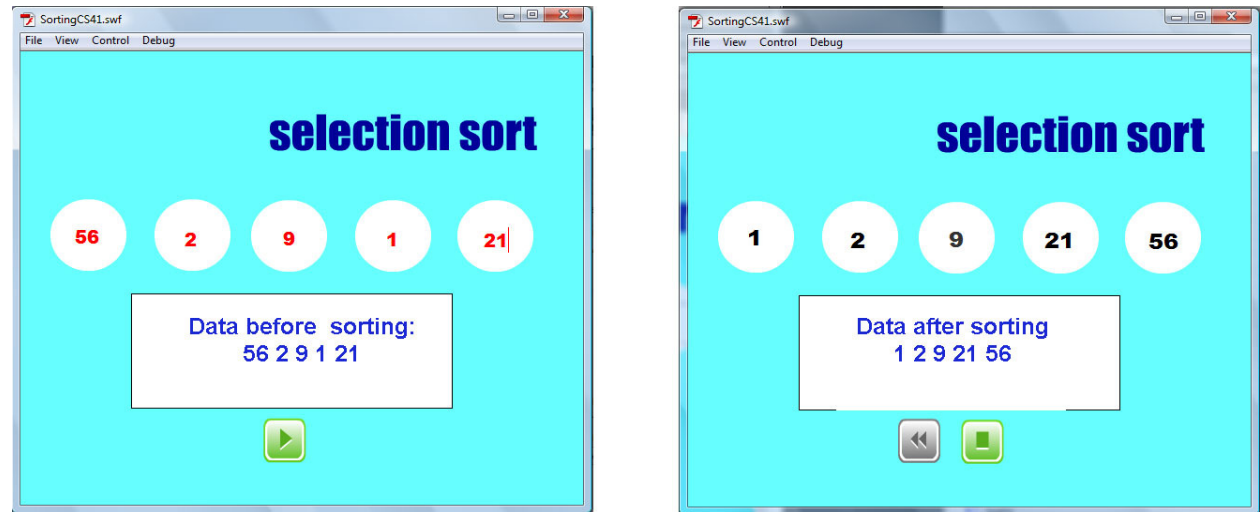

Figure 6. Flash movie presents the sorting of integer data type 
The International Journal of Multimedia \& Its Applications (IJMA) Vol.3, No.1, February 2011
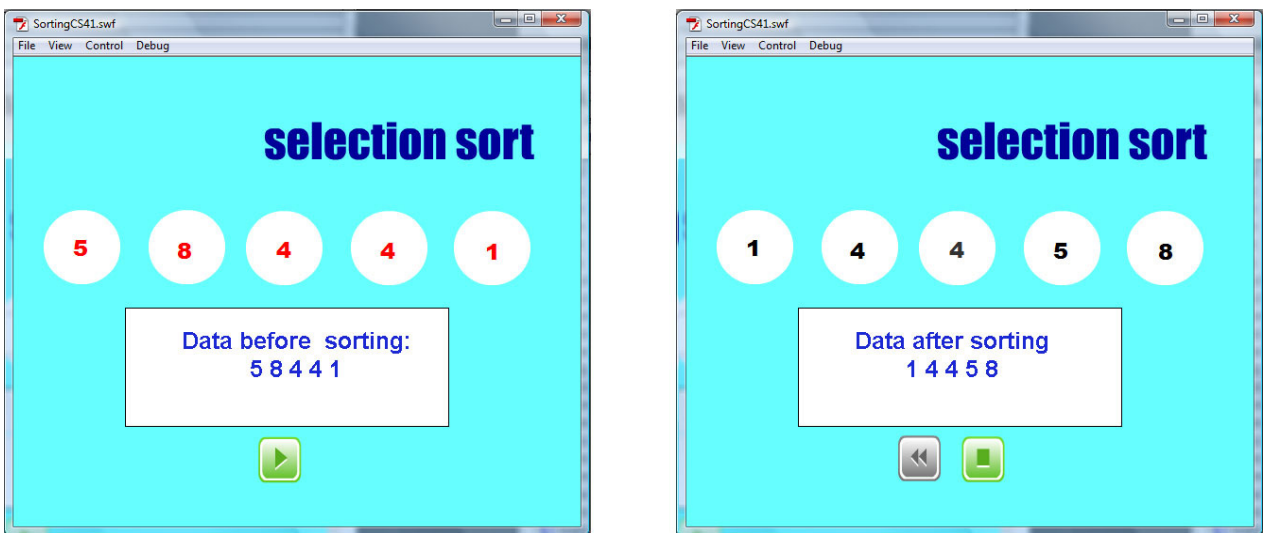

Figure 7. Flash movie presents the sorting of two elements of array with the same value
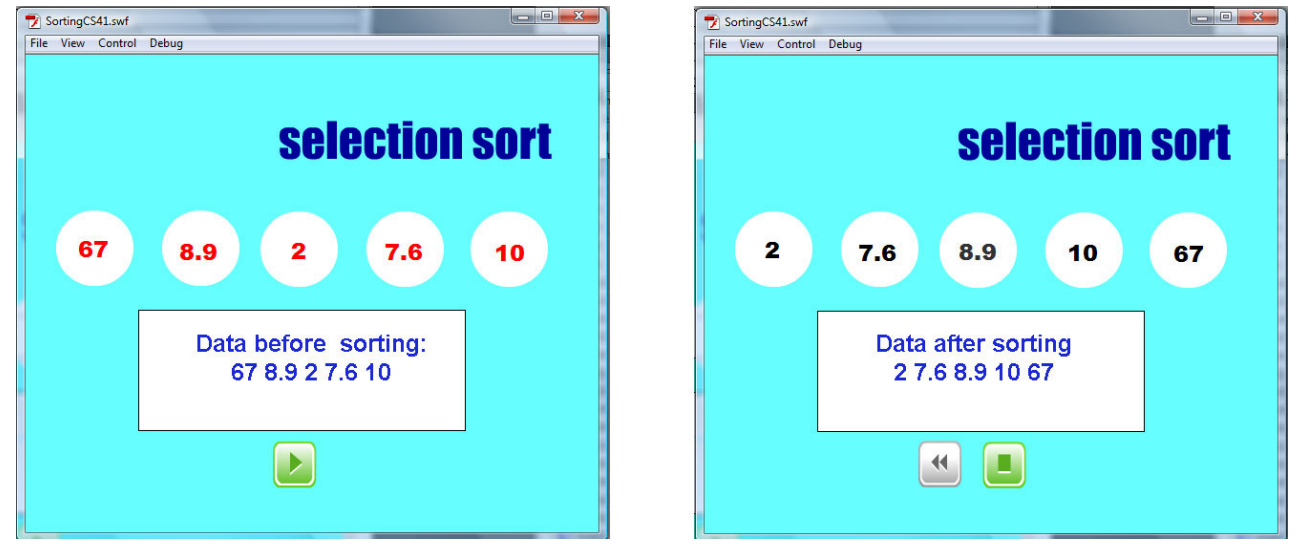

Figure 8. Flash movie presents the sorting with integer and real data type 

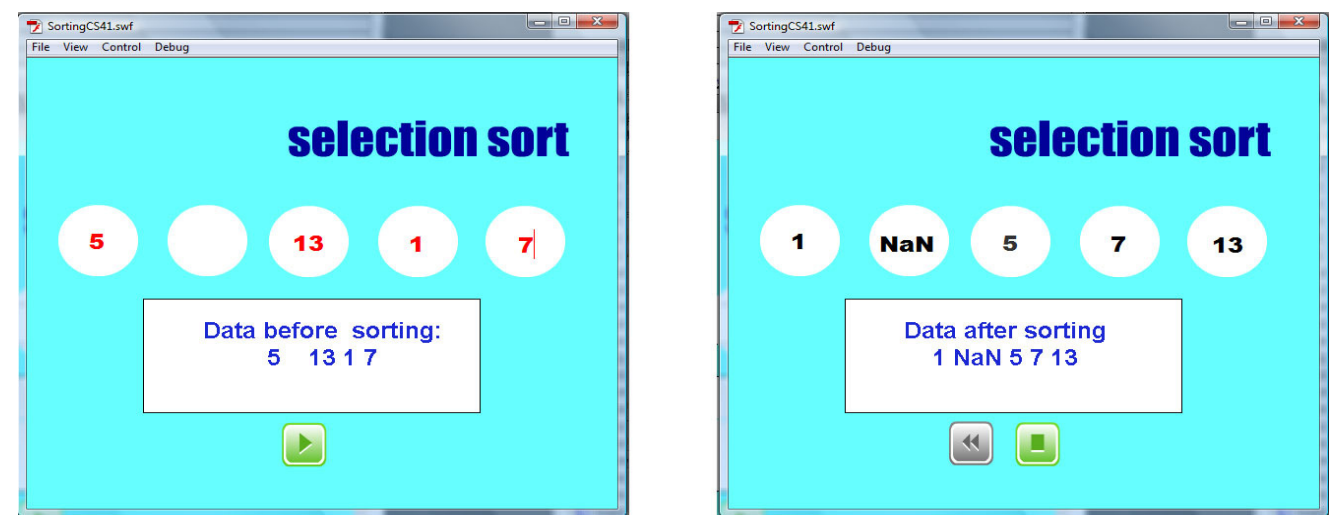

Figure 9. Flash movie presents the sorting with a blank element of array

The fourth testing is sorting with a blank element of data, i.e, the second element of array is blank. Figure 9 presents data before and after sorting, that the second element is presented with $\mathrm{NaN}$. The position of array with blank value is still not be changed by sorting process, and is still remain The fifth testing is sorting with character or string data type of elements of array. Before sorting, the elements are fill with character and string, and they are assigned with $\mathrm{NaN}$ after sorting, as can be seen in Figure 10. The problem is caused of the numeric assigning in array generating before sorting. After conducting the main field testing, it indicates that students increase their motivation in creating and coding according to variety sorting method using particular programming language they have learned.
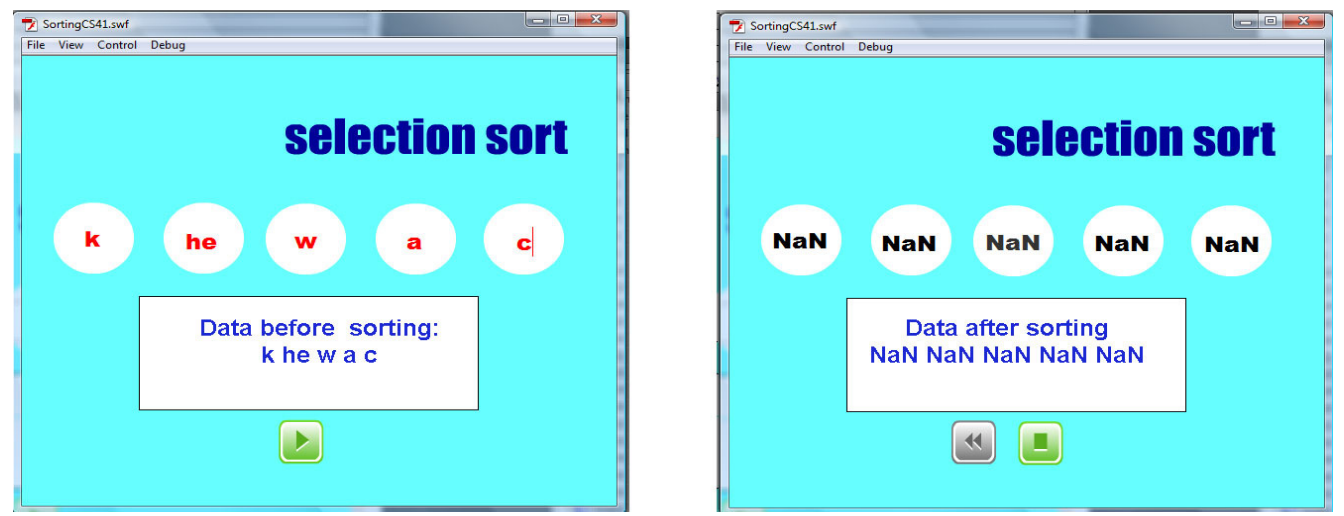

Figure 10. Flash movie presents the sorting with character or string data type

\section{Conclusions}

Through this paper the selection sorting algorithm visualization has been presented. Some details about implementation of selection sorting algorithm in Flash and ActionScript programming have been described. The visualization and the interactivity have been well tested by the students at the Department of Informatics Universitas Persada Indonesia YAI, and indicates that: 
The International Journal of Multimedia \& Its Applications (IJMA) Vol.3, No.1, February 2011

1. Student understand easily the concept of selection sort by looking at the visualization. Learning material text is more affective if it is provided with graphic, animation, or video to be learned by student.

2. Multimedia, particularly the visualization increases student motivation in algorithm learning and code creating, according to variety sorting method using particular programming language they have learned, i.e. $\mathrm{C}++$, Java, Visual Basic, and ther programming languages.

3. Adobe Flash is a timeline-based authoring and object-oriented programming tools that can be used to develop a scientific visualization. Adobe Flash with ActionScript programming tools can be used to make logic and mathematics operation.

\section{FURTHER RESEARCH}

The study shows that some aspects of Flash with ActionScript, which we can classify into design factor, multimedia factor, and programming factor, succeeds in generating algorithm visualization. Each aspect contains some activity that should be involved in multimedia development methodology. For further research, the application requires to be completed with visualization of other sorting algorithm methods and can be implemented for numeric, character, and string data type.

\section{REFERENCES}

[1] Semiawan, Conny R, (2009) Landasan Pembelajaran dalam Perkembangan Manusia, Jakarta: Center for Human Capacity Development.

[2] Sfenrianto, (2009) “A Model of Adaptive E-Learning System Based on Student's Motivation”, Proceedings from ICCIT-09: International Conference on Creative Communication and Innovative Technology, 2009. Tangerang: CCIT Journal.

[3] Sedgewick, Robert, (2001) Algorithms in C++, Third Ediition, Massachusetss: Addison-Wesley

[4] Tenenbaum M, Aaron \& Augenstein, Moshe J, (1981) Data Structures Using Pascal, Englewoods Cliffs, Prentice Hall.

[5] Hearn, Donald, and Pauline Baker, (1996) Computer Graphics C Version, 2nd edition. Upper Saddle River, NJ: Prentice Hall International, Inc.

[6] Vaughan, Tay, (2006) Multimedia Making it Work, Yogyakarta: Andi Publisher.

[7] Anleigh, Prabath K \& Thakar, Kiran, (1997) Multimedia Systems Design, Upper Saddle River: Prentice Hall.

[8] Bhatnager, Gaurav, Sikha Metha and Sugata Mitra, (2001) Introduction to Multimedia Systems, London: Academic Press.

[9] Luther, Arc C, (1994) Authoring Interactive Multimedia. Boston: AP Professional.

[10] Sutopo, Ariesto H, (2003) Multimedia Interaktif dengan Flash. Yogyakarta: Graha ilmu.

[11] Ypenburg, Derrick, (2009) ActionScript 3.0, Berkeley, CA: Peachpit Press.

[12] Franklin, Derek \& Jobe Makar, (2002) Macromedia Flash MX ActionScripting Advanced Training from the Source, Berkeley, CA: Macromedia Press.

[13] Sutopo, Ariesto H, (2003) Integrasi Flash dengan ASP, Jakarta: Elex Media Komputindo. 
The International Journal of Multimedia \& Its Applications (IJMA) Vol.3, No.1, February 2011

\section{Authors}

Hadi Sutopo was born in Cilacap, Indonesia on April 15, 1945. He is Doctor of Education in Educational Technology of the Jakarta State University, graduated in November 2009. In 1998 he earned Master of Information Systems at Post Graduate Program Gunadarma University, Jakarta. In 1995 he graduated from the Universitas Persada Indonesia YAI. Jakarta, majoring in Informatics.

Hadi is currently a lecturer of Multimedia at the Universitas Persada Indonesia YAI and some other universities in Jakarta, Indonesia since 1998. He wrote many books on multimedia and information technology. The books are Pemrograman Berorientasi Objek dengan Java (Yogyakarta, Indonesia: Graha Ilmu, 1995), Desain Buku dengan Adobe InDesign Jakarta, Indonesia: Elex Media Komputindo, 2006), and Pemrograman Flash dengan PHP dan MySQL (Yogyakarta, Indonesia: Graha Ilmu, 2007). Current interest research is information technology especially multimedia.

Dr. Hadi Sutopo, MMSI is a member of Indonesian Association of Educational Technology (IPTPI) and Association of Education and Communication Technology (AECT). He works in editorial team of Educational Technology Journal and Multimedia Journal in Jakarta, Indonesia.

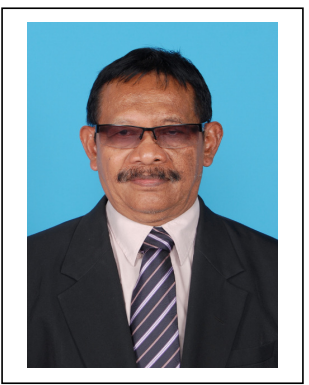

